\title{
Psychiatric morbidity in epilepsy: a case controlled study of adults receiving disability benefits
}

\author{
Sigurjon B Stefansson, Elias Olafsson, W Allen Hauser
}

\begin{abstract}
Objective-To compare the prevalence of non-organic psychiatric disorders among disabled patients of normal intelligence with epilepsy with the prevalence of similar psychiatric disorders among age and sex matched disabled patients with other somatic diseases.

Methods-A case-control study was carried out in Iceland among people receiving disability benefits using information available at the State Social Security Institute. There were 344 patients with epilepsy in Iceland 16 to 66 years of age (inclusive) receiving disability benefits in 1995. By excluding mentally retarded patients, autistic patients, and patients with organic psychoses, 241 index cases with epilepsy qualified for the study. For each case two age and sex matched controls were selected from all patients receiving disability benefits who had cardiovascular diseases, respiratory diseases, or arthropathies. The same exclusion criteria were applied to the controls as the index cases. In both patient groups psychiatric diagnoses were classified into one of the four following categories: (1) psychotic illness; (2) neurotic illness or personality disorders; (3) alcohol or drug dependence or misuse; and (4) other mental disorders.
\end{abstract}

Results-Psychiatric diagnosis was present among $35 \%$ ( 85/241) of the cases compared with $30 \%(143 / 482)$ of the controls $(p=0.15)$. There was a difference in the distribution of the two groups into different psychiatric categories $(p=0.02)$. This was mainly due to an excess of men in the index group with psychosis, particularly schizophrenia or paranoid states.

Conclusion-The results suggest that there is not a difference in the prevalence of non-organic psychiatric disorders among disabled patients of normal intelligence with epilepsy compared with patients with other disabling somatic diseases. However, the data indicate that when psychopathology is present disabled patients with epilepsy are more likely to have psychotic illness than the other disabled patients.

(F Neurol Neurosurg Psychiatry 1998;64:238-241)

Keywords: epilepsy; disability; psychiatric disorders

Psychiatric illnesses are generally considered to be more common among patients with epilepsy than in the population at large. ${ }^{12}$ Several factors have been suggested to explain increased psychopathology in epilepsy-for example, epileptogenic brain dysfunction, antiepileptic medication, psychosocial difficulties, and disability associated with epileptic seizures. These issues raise the question whether patients with epilepsy are more likely to develop psychiatric illnesses than other patients with disabling somatic diseases. Whitman et $a l^{\beta}$ analysed previously published Minnesota multiphasic personality inventory profiles of patients with epilepsy, and patients with other neurological or other chronic physical illnesses. They reported that patients with epilepsy were at higher risk of developing psychopathological disorders than the general population but the risk was not greater than among patients with other chronic diseases. Whitman et $a l^{\beta}$ also noted that when psychopathology was present it tended to be more severe in the epilepsy group than in the other patient groups (the probability of psychosis was higher among the patients with epilepy). These investigators found no difference in the frequency of psychopathology when comparing patients with epilepsy classified as having temporal lobe epilepsy with those having generalised epilepsy. ${ }^{3}$ However, Edeh and Toone, ${ }^{4}$ in a study of 88 patients with epilepsy drawn from general practice, found that the risk of developing psychiatric illness was higher among patients with temporal lobe epilepsy and other focal epilepsy than among patients with primary generalised epilepsy. Fiordelli et $a \bar{l}$ found no increase in risk of psychiatric disorders among 100 patients with cryptogenic epilepsy attending an outpatient clinic compared with 100 age and sex matched patients undergoing minor surgery but otherwise healthy. In a community based study by Trostle $e t a l,{ }^{6}$ the patients with epilepsy were generally found to be well adjusted socially and psychologically and most reported few problems in coping with their illness.

There are clearly conflicting data regarding psychiatric morbidity in epilepsy. The present study was carried out to test further the conclusion reached by Whitman et al that the risk of developing psychiatric disorders among patients with epilepsy is not higher than among patients with other chronic illnesses. In particular, we were interested in determining the prevalence of those psychiatric disorders that do not have a well established association with epilepsy. For this purpose we compared the prevalence of psychiatric diagnoses in a group of patients with epilepsy and a control group of other patients receiving disability benefits from 

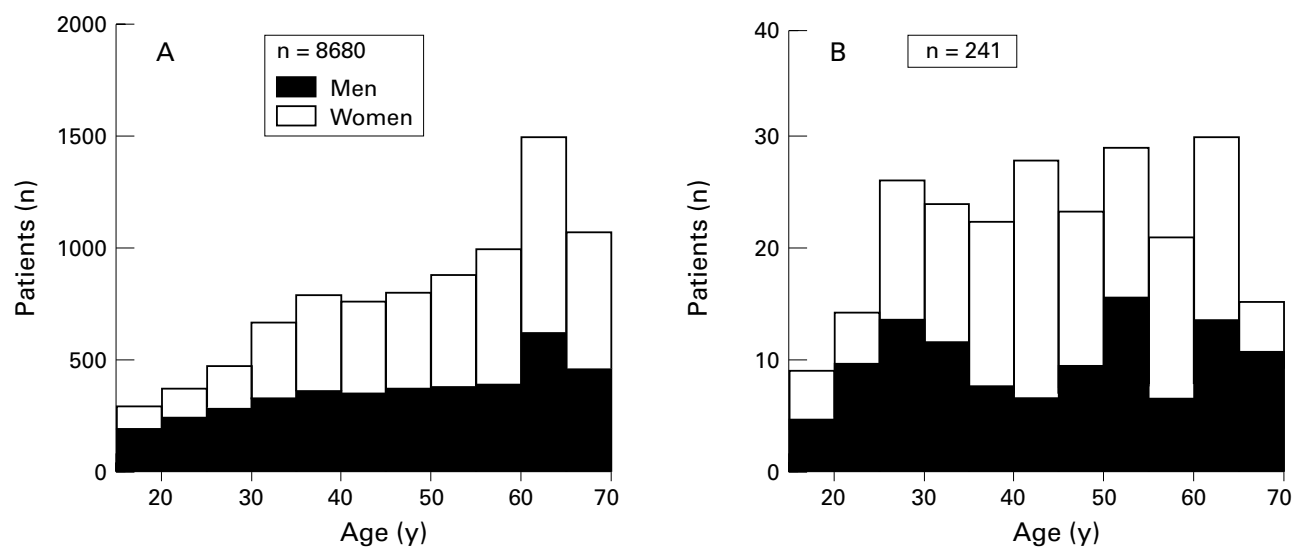

Histograms that show the ages of $(A)$ patients receiving disability benefits from the State Social Security Institute of Iceland in 1995, and (B) the epileptic patients included in this study derived from the same source.

the State Social Security Institute of Iceland (SSSI) in 1995. Patients with mental retardation, autism, organic psychoses, or other mental disorders due to organic brain conditions were excluded from the study.

\section{Methods}

Every resident of Iceland is covered by a comprehensive national health insurance scheme managed by the SSSI. Disability benefits are payable to persons from 16 to 66 years of age, and eligibility is based on financial expenses and loss of earning capacity due to illness. There are two grades of disability: mild/ moderate disability implies substantial expense or inability to earn more than half of what might be expected by healthy persons; severe disability implies inability to earn more than one fourth of what might be expected by those who are healthy. Physicians working for the SSSI determine the grade of disability based on the applicant's medical history and social circumstances. Every patient receives one or more medical diagnoses which in 1995 were based on the Ninth Revision of the International Classification of Diseases (ICD-9). ${ }^{7}$ In 1995 the population of Iceland between the ages of 16 and 66 years was 185108 (men $51 \%$; women $49 \%$ ). ${ }^{8}$ The number of disability claimants in 1995 was 3535 men and 5145 women or $4.7 \%$ of the population between the ages of 16 and 66 (figure, A). Of all men, 15\% had mild/moderate disability and $85 \%$ had severe disability. Of all women, $21 \%$ had mild/ moderate disability and $79 \%$ had severe disability. This study was carried out by using statistical information and case records about the disability claimants available at the SSSI.

INDEX CASES

Before selecting the index cases all patients with the following diagnoses were excluded: mental retardation (ICD-9: 317-319); psychoses with origin specific to childhood (ICD-9: 299); organic psychotic conditions (ICD-9: 290-294); and mental disorders following organic brain damage (ICD-9: 310). The epileptic index group consisted of 241 patients (men: 103; women: 138); the mean age was 43.8 years (men 43.6 ; women: 43.9 ); SD 14.0 (men 15.2; women 13.2). Figure B shows the age distribution of the epileptic patients. Patients excluded were 99 with mild to severe mental retardation, three autistic patients, and one patient with organic psychosis. Of the men $12 \%$ had mild/moderate disability and $88 \%$ had severe disability. Of the women $21 \%$ had mild/moderate disability and $79 \%$ had severe disability.

CONTROLS

The control group of 482 patients was selected from a sample of all non-epileptic patients receiving disability benefits who were diagnosed according to the ICD-9 as having cardiovascular diseases (ICD-9: 390-459); respiratory diseases (ICD-9: 460-519); and arthropathies (ICD-9: 710-719); altogether 4193 subjects ( $37 \%$ men; $63 \%$ women). The same exclusion criteria were applied to the controls as the index cases. For each case two controls were selected by identifying subjects of the same sex whose date of birth was as close as possible to the date of birth of the index case. Of the 206 men in the control 23\% had mild/moderate disability and $77 \%$ had severe disability. Of the 276 women $25 \%$ had mild/moderate disability and $75 \%$ had severe disability.

PSYCHIATRIC CLASSIFICATION

All patients with psychiatric diagnoses were placed into one of the four following diagnostic categories, according to the ICD-9: (1) psychotic illness (ICD-9: 295-298); (2) neurotic illness or personality disorders (ICD-9: 300301); (3) alcohol or drug dependence/misuse (ICD-9: 303-305); and (4) other mental disorders (ICD-9: 306-316). When a patient had more than one psychiatric diagnosis, the diagnosis with the lowest ICD-9 number was selected. Patients with psychotic illness or major depressive illness were further divided into the three following subcategories: (1) schizophrenia (ICD-9: 295); (2) affective psychoses (ICD-9: 296); (3) paranoid states and other non-organic psychoses (ICD-9: 297 and 298). A patient was placed into one of these subcategories after a psychiatrist had reviewed the medical information available at the SSSI on which the diagnosis was based. Statistical comparison between groups was 
Table 1 Psychiatric disorders in index and control patients

\begin{tabular}{lll}
\hline Psychiatric diagnoses & $\begin{array}{l}\text { Index patients }(n=241) \\
M / F=103 / 138\end{array}$ & $\begin{array}{l}\text { Control patients }(n=482) \\
M / F=206 / 276\end{array}$ \\
\hline All psychiatric diagnoses & $85(35.3)^{\star} \mathrm{M} / \mathrm{F}=40 / 45$ & $143(29.7)^{\star} \mathrm{M} / \mathrm{F}=56 / 87$ \\
Psychoses (ICD-9: 295-298) & $15(6.2) \mathrm{M} / \mathrm{F}=8 / 7$ & $11(2.3) \mathrm{M} / \mathrm{F}=2 / 9$ \\
Neurotic illness or personality disorders (ICD-9: $300-301)$ & $44(18.3) \mathrm{M} / \mathrm{F}=17 / 27$ & $102(21.0) \mathrm{M} / \mathrm{F}=37 / 65$ \\
Alcohol and drug dependence or misuse (ICD-9: $303-305)$ & $12(5.0) \mathrm{M} / \mathrm{F}=7 / 5$ & $11(2.3) \mathrm{M} / \mathrm{F}=7 / 4$ \\
Other non-psychotic disorders (ICD-9: 306-316) & $14(5.8) \mathrm{M} / \mathrm{F}=8 / 6$ & $19(4.0) \mathrm{M} / \mathrm{F}=10 / 9$ \\
\hline
\end{tabular}

Values are $\mathrm{n}(\%)$.

* Calculations of percentages are based on total number of epileptic $(n=241)$ and control $(n=482)$ patients respectively.

Table 2 Psychoses in index and control patients

\begin{tabular}{lll}
\hline Psychiatric diagnoses & Index patients $(n=15)$ & Control patients $(n=11)$ \\
\hline Schizophrenia (ICD-9: 295) & $3(1.2)^{\star} \mathrm{M} / \mathrm{F}=2 / 1$ & $2(0.4)^{\star} \mathrm{M} / \mathrm{F}=0 / 2$ \\
Affective psychoses (ICD-9: 296) & $8(3.3) \mathrm{M} / \mathrm{F}=3 / 5$ & $8(1.7) \mathrm{M} / \mathrm{F}=2 / 6$ \\
Paranoid states and other non-organic psychoses (ICD-9: 297-298) & $4(1.7) \mathrm{M} / \mathrm{F}=3 / 1$ & $1(0.2) \mathrm{M} / \mathrm{F}=0 / 1$
\end{tabular}

Values are $\mathrm{n}(\%)$.

${ }^{\star}$ Calculations of percentages are based on total number of epileptic $(n=241)$ and control $(n=482)$ patients respectively.

carried out by using a $\chi^{2}$ test. Yates' correction was used with $2 \times 2$ contingency tables.

\section{Results}

Psychiatric diagnoses were present in 85 out of the 241 index cases $(35.3 \%)$ and 143 out of the 482 control cases $(29.7 \%$, table 1$)$. This difference was not significant $\left(\chi^{2}=2.1, \mathrm{df}=1\right.$; $\mathrm{p}=0.15)$. However, when men and women were analysed separately there was an indication of an increased prevalence of psychiatric illness in men with epilepsy compared with their controls $\left(\chi^{2}=3.8 ; \mathrm{df}=1 ; \mathrm{p}=0.05\right)$ but not in women $\left(\chi^{2}=0.01 ; \mathrm{df}=1 ; \mathrm{p}=0.9\right)$. When the prevalence of psychiatric illness was compared between men and women in each group separately, there was no difference between the sexes in the index group $\left(\chi^{2}=0.7 ; \mathrm{df}=1 ; \mathrm{p}=0.4\right)$ or in the control group $\left(\chi^{2}=0.8 ; \mathrm{df}=1 ; \mathrm{p}=0.3\right)$.

Table 1 shows the distribution of the index and control patients into the four main psychiatric categories. A significant difference in the distribution of the two groups was present $\left(\chi^{2}=10.4 ; \mathrm{df}=3 ; \mathrm{p}=0.02 ;\right)$. This difference was not present when the women were analysed separately $\left(\chi^{2}=3.7 ; \mathrm{df}=3 ; \mathrm{p}=0.3\right)$ but was present for the men $\left(\chi^{2}=8.8 ; \mathrm{df}=3 ; \mathrm{p}=0.03\right)$. By comparing observed and expected values it was evident that the difference was mainly due to an excess of men with psychosis in the epilepsy group (eight of the 10 men with psychosis) and it disappeared when the data were analysed without the cases in the psychosis category $\left(\chi^{2}=2.1 ; \mathrm{df}=2 ; \mathrm{p}=0.3\right)$.

There were 15 index cases and 11 controls with psychosis diagnosis. Their distribution into the three main psychosis subcategories (table 2 ) was not significantly different $\left(\chi^{2}=1.4\right.$; $\mathrm{df}=2 ; \mathrm{p}=0.5)$. However, when the index group $(n=241)$ and the control group $(n=482)$ were compared with regard to the number of patients with psychosis there was a significant excess of index cases with psychosis $\left(\chi^{2}=6.1\right.$; $\mathrm{df}=1 ; \mathrm{p}=0.01)$. This difference between the two groups persists when the number of patients with schizophrenia-like psychosis (schizophrenia and paranoid states) were compared $\left(\chi^{2}=4.6 ; \mathrm{df}=1 ; \mathrm{p}=0.03\right)$ but was not present for affective psychosis $\left(\chi^{2}=1.35 ; \mathrm{df}=1\right.$; $\mathrm{p}=0.24)$.

\section{Discussion}

Based on a recent study of the prevalence of epilepsy in Iceland, it is estimated that there are about 600 persons 16 to 66 years of age with epilepsy in the country. ${ }^{9}$ The present data therefore indicate that about half of this population with epilepsy is receiving disability benefits.

After excluding patients with mental retardation, autism, and organic mental illness from cases and controls, the percentage of disability claimants with epilepsy who had a psychiatric diagnosis $(35 \%)$ was not significantly different from that in the control group (30\%). These findings are in agreement with the results of Whitman et $a l^{\beta}$ that there is not an overall increase in prevalence of mental disorders in disabled patients with epilepsy compared with patients with other chronic somatic diseases. However, $6.2 \%$ of the patients in the index group compared with $2.3 \%$ in the control group had a diagnosis of psychotic illness. The difference was chiefly due to an overrepresentation of patients with schizophrenia and paranoid states in the index group. This suggests that when psychopathology is present, psychotic illness, particularly schizophrenia-like psychosis, is more likely to be associated with epilepsy than other chronic diseases.

Most studies have shown that epilepsy is more common among men than women..$^{10}$ In our population with epilepsy receiving disability benefits there are more women than men. This reflects the actual sex ratio of disability claimants in Iceland. In the general population of Iceland there are more men than women in the age group from 16 to 66 years and mortality is higher among the men. ${ }^{8}$ It is likely that socioeconomic reasons are mainly responsible for the excess of women on disability benefits. A possible explanation for our finding that men in the epilepsy group are more prone to have psychiatric disorders than the men in the control group is that a combination of epilepsy and psychiatric disorder is particularly difficult for men in the present day socioeconomic climate.

In an epidemiological survey of epilepsy in Iceland, carried out from 1960 to the end of 1964, Gudmundsson ${ }^{11}$ found that $7 \%$ of 987 
prevalence cases had a history of psychotic illness. In the study of Helgason ${ }^{12}$ of the 1895-7 Icelandic birth cohort the lifetime prevalence of non-organic psychiatric disorder was $27 \%$ at the age of 61 . Furthermore he found that the expectancy of becoming psychotic before the age of 61 was between $4 \%$ and $5 \%$. Stefansson et $a l^{13}$ using the diagnostic interview schedule, carried out a study of a cohort consisting of half of all Icelanders born in 1931. They found the lifetime prevalence of psychotic and major depressive disorders (using the DSM-III classification) to be about $6 \%$ in the cohort at the age of 57.

The figures presented in the studies of Gudmundsson, ${ }^{11}$ Helgason, ${ }^{12}$ and Stefansson et $a l^{13}$ are similar to those found in the present study but direct comparison is difficult because of methodological differences. The actual lifetime prevalence of psychiatric disorders among our index cases should be somewhat higher than the figures we found because the diagnoses used for evaluation of disability reflect more the present state of the patient than previous episodes of psychiatric illness.

Schizophrenia-like psychoses have been reported to be equally common among men and women with epilepsy. ${ }^{14}$ When patients with a diagnosis of schizophrenia or paranoid states were combined (schizophrenia-like psychosis) in the present study, all three patients in the control group were women but in the epilepsy group there were five men and two women. For affective psychosis there is a female preponderance both in the epilepsy group and the control group.

The conclusion of the present study is that in Iceland psychiatric disorders are equally common among those disability claimants with epilepsy and those with other chronic somatic diseases. However, there are indications that the patients with epilepsy are more liable to develop psychotic illness, particularly schizophrenia-like illness. We estimate that disability claimants with epilepsy represent about half of those patients 16 to 66 years of age with epilepsy in the general population. The other patients with epilepsy in this age group are most likely fully employed. Whether psychiatric disorders are any more common among them than in the working population at large is a question worth further investigation.

This investigation was partly supported by the Icelandic Science Council and the American National Institute of Health (grant R01-NS 32663).

1 Engel J. Seizures and epilepsy. Philadelphia: Davis, 1989:28199 .

2 Trimble M. Biological psychiatry, 2nd ed. Chichester: Wiley, 1996:266-90.

3 Whitman S, Hermann BP, Gordon AC. Psychopathology in epilepsy: how great is the risk? Biol Psychiatry 1984;19:21336 .

4 Edeh J, Toone B. Relationship between interictal psychopathology and the type of epilepsy. Br f Psychiatry 1987;151: thology

5 Fiordelli E, Beghi E, Bogliun G, et al. Epilepsy and psychiatric disturbance. A cross-sectional study. $\mathrm{Br} \mathcal{F}$ Psychiatry 1993;163:446-50.

6 Trostle JA, Hauser WA, Sharbrough FW. Psychologic and social adjustment to epilepsy in Rochester, Minnesota. Neurology 1989;39:633-7.

7 World Health Organization. International classification of diseases. Manual of the international statistical classification of diseases, injuries, and causes of death. Vol 1, 9th revision. London: Her Majesty's Stationary Office, 1977:177-213.

8 Landshagir. Statistical Yearbook of Iceland 1996. Reykjavik:

9 Olagstofa Islands (Statistics Iceland), 1996 . Olafsson E, Hauser WA, Ludvigsson P, et al. Incidence and
prevalence of epilepsy in rural Iceland. Epilepsia 1994; prevalence of ep

10 Sander JWAS, Shorvon SD. Incidence and prevalence studies in epilepsy and their methodological problems: a review. f Neurol Neurosurg Psychiatry 1987;50:829-39.

11 Gudmundsson G. Epilepsy in Iceland. A clinical and epidemiological investigation. Acta Neurol Scand 1966;43(suppl 25): $1-124$.

12 Helgason T. Epidemiology of mental disorders in Iceland. A psychiatric and demographic investigation of 5395 Icelanders. Acta Psychiatr Scand 1964;40(suppl 173):1-258

13 Stefansson JG, Lindal E, Bjornsson JK, et al. Lifetime prevalence of specific mental disorders among people born in Iceland. Acta Psychiatr Scand 1991;84:142-9.

14 Toone B. Psychoses and epilepsy. In: Reynolds EH, Trimble MR, eds. Epilepsy and psychiatry. Edinburgh: Churchill Livingstone, 1981:113-37. 